\title{
BMJ Open Experience of the COVID-19 pandemic as lived by patients with hip and knee osteoarthritis: an Italian qualitative study
}

\author{
Simone Battista (D) , ${ }^{1,2}$ Andrea Dell'Isola (D) , ${ }^{2}$ Mattia Manoni, ${ }^{1}$ Martin Englund, ${ }^{2}$ \\ Alvisa Palese (D) , ${ }^{3}$ Marco Testa ${ }^{1}$
}

To cite: Battista S, Dell'Isola A, Manoni M, et al. Experience of the COVID-19 pandemic as lived by patients with hip and knee osteoarthritis: an Italian qualitative study. BMJ Open 2021;11:e053194. doi:10.1136/ bmjopen-2021-053194

- Prepublication history and additional supplemental material for this paper are available online. To view these files, please visit the journal online (http://dx.doi.org/10.1136/ bmjopen-2021-053194).

Received 06 May 2021 Accepted 19 0ctober 2021

Check for updates

(C) Author(s) (or their employer(s)) 2021. Re-use permitted under CC BY-NC. No commercial re-use. See rights and permissions. Published by BMJ.

${ }^{1}$ Department of Neurosciences, Rehabilitation, Ophthalmology, Genetics, Maternal and Child Health, University of Genova,

Campus of Savona, Savona, Italy

${ }^{2}$ Clinical Epidemiology Unit, Orthopaedics, Department of Clinical Sciences, Lund University, Lund, Sweden

${ }^{3}$ Department of Medical

Sciences, University of Udine, Udine, Italy

Correspondence to

Simone Battista;

simone.battista@edu.unige.it

\section{ABSTRACT}

Objective To examine the experience of the COVID-19 pandemic as lived by people with hip and knee osteoarthritis $(\mathrm{OA})$, in Italy.

Design A qualitative study based on semi-structured interviews.

Setting Urban and suburban areas in northern Italy. Participants A total of 11 people with $0 \mathrm{~A}$ were enrolled through a purposeful sampling and completed the study. Primary outcome measure The experience of Italian people with OA during the COVID-19 pandemic.

Results Four themes were brought to the forefront from the analysis of the interviews. (1) Being Stressed for the Limited Social Interactions and for the Family Members at High Risk of Infection, as the interviewees were frustrated because they could not see their loved ones or felt a sense of apprehension for their relatives. (2) Recurring Strategies to Cope with the Pandemic such as an active acceptance towards the situation. (3) Being Limited in the Possibility of Undergoing OA Complementary Treatments and Other Routine Medical Visits. (4) Being Unaware of the Importance of Physical Activity as First-Line Interventions which was an attitude already present before the pandemic.

Conclusion The COVID-19 pandemic and related restrictions impacted the quality of life and the care of individuals with hip and knee OA. The social sphere seemed to be the most hindered. However, the interviewees developed a good level of acceptance to deal with the pandemic. When it came to their care, they faced a delay of routine medical visits not related to $O A$ and of other complementary treatments (eg, physical therapies) to manage $\mathrm{OA}$. Finally, a controversial result that emerged from these interviews was that first-line interventions for $\mathrm{OA}$ (ie, therapeutic exercise) was not sought by the interviewees, regardless of the restrictions dictated by the pandemic. Policy-making strategies are thus necessary to support the awareness of the importance of such interventions.

\section{INTRODUCTION}

Health emergencies, such as the COVID-19 pandemic, can cause burdensome psychosocial consequences on the general population, due to disease-related fear and anxiety,

\section{STRENGTHS AND LIMITATIONS OF THIS STUDY}

$\Rightarrow$ This is the first study that highlights how patients with osteoarthritis experienced the COVID-19 pandemic in Italy.

$\Rightarrow$ Even if no follow-up interviews were performed, the participants still agreed with their narratives during the member-checking phase performed at the end of the study.

$\Rightarrow$ The participants were interviewed in different periods marked by different governmental restrictions regarding the pandemic.

$\Rightarrow$ All the interviewees lived in northern Italy. However, this was among the most affected areas in all Europe.

large-scale social isolation and the frequent overabundance of (mis)information on different social media outlets. ${ }^{1}$ In particular, the Italian population experienced a broader array of mental health symptoms linked to the COVID-19 pandemic, such as depression, anxiety, insomnia and high perceived stress ${ }^{2}$ which have been linked to lowering the quality of life, and worsening symptoms of people affected by different pain conditions. ${ }^{3-8}$

Moreover, due to the COVID-19 pandemic outbreak, the WHO recommended postponing treatments considered not urgent, such as those delivered for several musculoskeletal conditions as osteoarthritis (OA). ${ }^{9}$ The management of these patients is mainly based on therapeutic exercise and education that are recommended as first-line interventions by several international clinical practice guidelines (CPGs). ${ }^{10-13}$ These treatments are principally delivered by physiotherapists, due to their unique expertise in planning and prescribing therapeutic exercises, and their capacity to promote tailored education programmes for these patients. ${ }^{14}$ As a result of the COVID-19 pandemic restrictions, patients with different musculoskeletal 
conditions experienced limitations in the access to healthcare professionals worldwide, which turned into a worsening of their quality of care. ${ }^{15-17}$

Individuals with OA tend to suffer from several comorbidities, such as obesity and cardiovascular diseases, which are both linked to inadequate levels of physical activity. ${ }^{18}$ Moreover, exercise has been shown to have benefits that go beyond joint health, reducing the risk of developing a wide array of comorbidities and promoting a healthy lifestyle. ${ }^{19}$ Therefore, the limitations imposed during the lockdowns, that severely limited also the possibility to engage in physical activity, ${ }^{20}$ may have negatively influenced the care and the quality of life of these patients.

In light of this, the present study explores the experience of Italian patients with OA during the COVID-19 pandemic. Gaining insights on their lived experiences might inform decision-makers also at the policy levels, considering the high burden of $\mathrm{OA}$ at the individual and socioeconomical level. ${ }^{21-23}$

\section{METHODS}

\section{Study design}

This study followed an ecological paradigm, naturalistic epistemology and philosophy of phenomenological research ${ }^{24-26}$ Specifically, a descriptive phenomenological qualitative study, ${ }^{26}$ based on semi-structured interviews, was performed. This study was conducted following the Declaration of Helsinki and it is here reported according to the Standards for Reporting of Qualitative Research (online supplemental table 1) for qualitative studies. ${ }^{27}$

\section{Participants}

Purposeful sampling was adopted by accessing participants living in different geographical areas, both urban (core areas of cities) and suburban (residential areas that surround main cities), with different localisation of their pathology (ie, knee and hip) to maximise the variation in the experiences. ${ }^{28}$ Moreover, a snowball sampling was used by accessing individuals in the network of the first contacted participants with OA. ${ }^{28}$ People with physiciandiagnosed knee and hip OA, able to speak Italian and willing to participate, were considered eligible. Thus, those who reported joints other than hip or knee as the primary joints for OA symptoms were excluded. The recruitment was ended when the data saturation was achieved as judged by the two authors (SB and MM) who analysed the interviews. ${ }^{29}$ Patients were recruited through different physicians and healthcare professionals specialised in the rehabilitation of musculoskeletal disorders.

\section{Data collection method}

An ad-hoc interview guide was created by a pool of physiotherapists, psychologists, nurses and patients with OA, based on the existing literature (box 1 ).$^{10-13}$ The interview guide consisted of open questions exploring the influence of the COVID-19 pandemic outbreak (1) on their life, (2) on their care process and (3) on their level

\section{Box 1 Interview guide}

\section{Questions}

(1) Would you like to tell me how you lived this pandemic?

(2) Would you like to tell me if this pandemic had an impact on your quality of life? If so, in which way?

(3) Would you like to tell me if this pandemic had an impact on your care? If so, in which way?

$(3 A)^{*}$ For instance, in your routine physical activity? Did it change from before the pandemic?

$(3 \mathrm{~B})^{*}$ For instance, in your routine visit for $\mathrm{OA}$ with healthcare professionals?

$(3 \mathrm{~B})^{\star}$ For instance, in your routine visit with healthcare professionals for other healthcare problems you may have?

(4) How are you finding the access to the healthcare system in this moment?

(5) Is there anything else you would like to add?

*Questions that was asked if the patients did not mention themselves the topic. $O A$, osteoarthritis.

of physical activity. Follow-up questions were frequently used to further investigate the patients' perception. Examples of these questions were, 'Can you give me an example?' and 'Can you explain to me what you mean with this sentence?'. At the beginning of each interview, all patients filled in the informed consent and provided their demographic (ie, age, gender, nationality, job/retirement, area of living) and clinical information (ie, joint(s) affected by $\mathrm{OA}$ and years living with the pathology) which were registered on an electronic sheet by the interviewer.

In-depth semi-structured interviews were performed by SB from October 2020 to March 2021 and lasted approximately 1 hour each. SB is a physiotherapist, a $\mathrm{PhD}$ student who received training in advanced qualitative methodologies, with experience in conducting semistructured interviews. SB identifies himself as male. He had no close relationships with any of the participants, who were not aware of his professional background. Due to the COVID-19 pandemic outbreak, the interviews were not performed in presence, but either by telephone or videoconferencing and they were conducted only with the interviewee. An audio-visual recording of each interview was produced. The interviews were then transcribed verbatim by two authors ( $\mathrm{SB}$ and $\mathrm{MM}$ ).

\section{Data analysis}

A theme-based analysis was performed. ${ }^{30}$ The interview transcripts were read several times by two authors (SB and $\mathrm{MM)}$ to obtain a general impression of the content. They are both $\mathrm{PhD}$ students ( $\mathrm{SB}$ is a physiotherapist, $\mathrm{MM}$ is a psychologist), trained in qualitative methods, and identify themselves as male. They both analysed first independently, and then jointly, the interview transcripts, as described below. Initial coding involved examining the data line by line to search for subthemes, themes, concepts and patterns. Meaning units were identified and framed into codes, representing significant and main aspects of the reported statements. Throughout this process, 
emerging codes were compared with previous codes to understand the impact of the COVID-19 pandemic outbreak on their life, their care process and, their level of physical activity and to generate focused codes. Hence, the focused codes and coding were merged and synthesised to extract final subthemes and themes. The themes were derived from the data and not identified in advance.

\section{Rigour and trustworthiness}

Multiple strategies were promoted to ensure the study rigour and trustworthiness. First of all, SB documented field notes ('Memos') after completing each interview to promote reflexivity. ${ }^{31}$ These memos were shared during research meetings for reflexive thoughts. Second, the research team met frequently to refine the themes and subthemes until a consensus on the final themes was achieved. Third, an audit trail containing meeting notes, analysis discussions and research decisions was continuously updated by SB and MM to enhance the dependability and confirmability of the study. ${ }^{31}$ An example of it is reported in table 1. Finally, a Synthesised Member Checking was used to improve the credibility of the results. ${ }^{32}$ Patients were asked if they wanted to participate in the member checking phase at the end of each interview. The member checking phase was held at the end of the analysis process. An extract of what was found during the analysis was sent to all interviewees, and they all agreed to what was outlined by the researchers.

\section{Patient and public involvement}

Patients with OA were included in the design of the study as they participated in the creation of the interview guide to be sure that the questions included were relevant for the studied population.

\section{RESULTS}

\section{Participants}

Thirteen Italian patients from northern Italy agreed to participate in the interviews. Two participants were not able to do the interviews because they did not understand the questions on both telephone and videoconference, since they had important auditory impairments. So far, eleven participants were included. Among them, six identified themselves as female and five as male. As far as the diagnosis was concerned, five participants reported having hip OA, three knee OA and three both hip and knee OA. Table 2 reported the demographic and clinical characteristics of the participants.

Four main themes summarised the COVID-19 pandemic as experienced by patients: (1) Being Stress for the Limited Social Interactions and for the Family Members at High Risk of Infection; (2) Recurring Strategies to Cope with the Pandemic; (3) Being Limited in the Possibility of Undergoing OA Complementary Treatments and Other Routine Medical Visits; and (4) Being Unaware of the Importance of Physical Activity as FirstLine Interventions.
Theme 1: Being Stressed for the Limited Social Interactions and for the Family Members at High Risk of Infection

The COVID-19 pandemic seems to have impacted the interviewees' social relationships in different ways. They reported psychological consequences induced by social isolation and apprehension towards the relatives who worked in high-risk areas. In addition, some of the participants could not see their relatives for a long time, and this caused them to feel a deep sense of loss. Hence, two subthemes emerged: Being Frustrated for not Seeing Beloved Ones and Being in Apprehension For the Relatives Who Worked in High-risk Areas.

\section{Subtheme 1A: Being Frustrated for not Seeing Beloved Ones}

Some participants reported a sense of frustration for not being able to see their beloved ones. The mandatory social isolation promoted by the Italian Government had an impact on the social life of the interviewees. In particular, the older ones seemed to be the most impacted by the imposed restrictions concerning the possibility to see relatives. Some of them could not see their relatives for a long period, with a burdensome impact on their emotional experience.

For us older people, not being able to see our grandchildren ... it is, well, you know... (Participant 9, female, retired).

The only thing was the detachment, five months without seeing my son, my niece and my brother ..." (Participant 2, female, retired).

\section{Subtheme 1B: Being in Apprehension For the Relatives Who Worked in High-risk Areas}

The participants felt anxious for their relatives who could not work from home and were exposed to high-risk environments such as hospitals and public transports. In this case, the participants seemed to be more worried about their relatives than themselves.

My sister still works in the hospital and this makes me quite anxious. (Participant 4, female, employed).

From a family point of view, having my wife going out every day to work in an exposed context gives me a bit to worry about. (Participant 6 , male, employed)

\section{Theme 2: Recurring Strategies to Cope with the Pandemic} All the interviewees seemed to have developed effective coping strategies to face the changes induced by the COVID-19 pandemic outbreak in their daily routine. In particular, they accepted the new reality and changed their lifestyle to better adapt to the situation. As a result, two shared subthemes were identified: Accepting the New Situation and Adapting One's Lifestyle to the New Situation.

\section{Subtheme2A: Accepting the New Situation}

The interviewees reported to have achieved a good level of active acceptance without resignation towards the general situation induced by the pandemic. They all agreed on the fact that they could not do anything about 
Table 1 Data synthesis by extracting and abstracting findings in common categories and themes

Abstraction: themes
Being Stressed for the
Limited Social Interactions
and for the Family
Members at High Risk of
Infection

Recurring Strategies to Cope with the Pandemic

\section{Abstraction:} subthemes

Being Frustrated for not Seeing Beloved Ones

\section{Being in}

Apprehension For the Relatives Who Worked in High-risk Areas.

Accepting the New Situation

\section{Codes defined by} researchers

Sense of detachment

Older people sense of Ioneliness

Being worried for relatives who work in the hospital

Being worried for relatives who work in other exposed context

Unexpected attitude towards the pandemic

Being fine with accepting what is going on

Adapting One's Lifestyle to the New Situation

Remote working as a possibility

More time to dedicate to other activities

$\begin{array}{ll}\text { Being Limited in the } & \text { Being Limited } \\ \text { Possibility of Undergoing } & \text { in Undergoing } \\ \text { OA Complementary } & \text { Conditional OA } \\ \text { Treatments and Other } & \text { Treatments }\end{array}$

Routine Medical Visits.
Being Unaware of the Importance of Physical Activity as First-Line Interventions

\section{Lack of Seeking of No previous physical Physical Activity activity \\ Before the Pandemic}

No external motivation to do physical activity

Lack of Seeking of Physiotherapy for OA Before the Pandemic

Lack of awareness
Example of quotes extracted from the interviews

The only thing was the detachment, five months without seeing my son, my niece and my brother ... (Participant 2, female, retired).

For us older people, not being able to see our grandchildren ... it is, well, you know ... (Participant 9, female, retired).

My sister still works in the hospital and this makes me quite anxious. (Participant 4, female, employed).

From a family point of view, having my wife going out every day to work in an exposed context gives me a bit to worry about. (Participant 6, male, employed)

Well, I'm being honest with you, I took it quite well, in the sense that I did not throw myself into crazy drama. It is obvious that being locked up for three months like this is not nice, but there was nothing I could do about it. (Participant 5 , female, retired).

That was the situation, there was nothing else to do, and that was that. (Participant 7, female, employed).

I managed to keep on working thanks to all the calls, all the virtual meetings. Through them I was able to carry on working so I never got bored. (Participant 10, male, employed).

We did things we were not able to do ... because there was no time. One thing, for example, which was nice, was organising the old photos we had in the house (Participant 3 , female, retired).

Well, I did not undergo the ESWT, ... after the holidays I thought I would go back and do it [the therapy], but in the meantime, they had closed the hospital again. (Participant 4, female, employed).

Limitation in undergoing The impact of COVID-19 on my knee [with OA] was that I was surgery forced to postpone surgery which should have taken place in February, to 6 or 7 months later. (Participant 9, female, retired).

Postponement of daily I have to do this check every year, as it is mandatory for medical check me. However, now, I can't do it, as it is not possible to book [a visit in a public hospital] and, for now, I cannot afford private healthcare, so I'll have to wait. (Participant 7, female, employed).

No possibilities to find the After the COVID-19 pandemic outbreak, it is almost general practitioner impossible to go there [to the GP]. (Participant 8, male, retired).

At that time(before the COVID-19 pandemic outbreak), I was not going to the gym anymore. I had not renewed my membership because it was difficult for me to go because of my symptoms. (Participant 4, female, employed).

... On my own initiative. I have never been pushed to do certain treatments [active exercise] in order to take care of osteoarthritis... then Covid has nothing to do with it(my not taking care of OA right now, during the pandemic) (Participant 11, male, employed).

I am not aware of their [physiotherapists'] role, so I cannot understand what they can do for my disease. (Participant 2, female, retired).

Lack of referral
No one has ever suggested me [to go to the physiotherapist] ... No one has ever told me that if I had gone to the physiotherapist twice a week, I would have felt better (Participant 10, male, employed). 
Table 2 Participants' demographic and clinical characteristics

\begin{tabular}{|l|l|}
\hline Age (years) (median (Q1, Q3)) & $65(52,70)$ \\
\hline Gender, N (\%) & $6(54)$ \\
\hline Female & $5(46)$ \\
\hline Male & \\
\hline Retired, N (\%) & $5(46)$ \\
\hline Yes & $6(54)$ \\
\hline No & \\
\hline Urban area, N (\%) & $6(54)$ \\
\hline Yes & $5(46)$ \\
\hline No & $2(1.75,4.5)$ \\
\hline Disease duration (years) (median (Q1, Q3)) & \\
\hline Diagnosis, N (\%) & $5(46)$ \\
\hline Hip OA & $3(27)$ \\
\hline Knee OA & $3(27)$ \\
\hline Hip and knee OA & $8(73)$ \\
\hline $\begin{array}{l}\text { Consulted a physiotherapist for joint } \\
\text { problems, N (\%) }\end{array}$ & \\
\hline Yes & $3(27)$ \\
\hline No & \\
\hline Q1, first quartile; Q3, third quartile. & \\
\hline
\end{tabular}

it, and they accepted the imposed restrictions for the sake of improving the pandemic situation.

Well, I'm being honest with you, I took it quite well, in the sense that I did not throw myself into crazy drama. It is obvious that being locked up for three months like this is not nice, but there was nothing I could do about it. (Participant 5, female, retired).

That was the situation, there was nothing else to do, and that was that. (Participant 7 , female, employed).

\section{Subtheme 2B: Adapting One's Lifestyle to the New Situation}

Some of the participants changed their daily routine to better adapt to the new reality imposed by the COVID-19 restrictions. In particular, the participants who were still working faced the new reality by transferring their face-toface work into digital work.

I managed to keep on working thanks to all the calls, all the virtual meetings. Through them I was able to carry on working so I never got bored. (Participant 10, male, employed).

Erm ... I sorted myself out, I am basically working three days from home, and two days from the office, this has allowed me to work quite well up to now. (Participant 6, male, employed).

Furthermore, some of them took advantage of the situation to do things they were not able to do before because of they lacked the time.
We did things we were not able to do $\ldots$ because there was no time. One thing, for example, which was nice, was organising the old photos we had in the house (Participant 3, female, retired).

Theme 3: Being Limited in the Possibility of Undergoing OA Complementary Treatments and Other Routine Medical Visits

The participants experienced limitations in the possibility to undergo the prescribed management that was mainly based on passive treatments. Moreover, these limitations were also found in the possibility to attend routine medical visits that patients had to do for other medical conditions. Hence, two main subthemes were developed: Being Limited in Undergoing Conditional OA Treatments and Being Limited in Undergoing Routine Medical Visits.

\section{Subtheme 3A: Being Limited in Undergoing Conditional OA Treatments}

Participants experienced some limitations regarding the possibility to undergo other OA treatments. As a result, some reported that these limitations were related to different non-surgical interventions such as infiltrations and physical therapies (eg, extracorporeal shock wave therapy).

Well, I did not undergo the ESWT, ... after the holidays I thought I would go back and do it [the therapy], but in the meantime, they had closed the hospital again." (Participant 4, female, employed).

Besides, some of the participants had to postpone their surgical intervention or the visit with their surgeon to plan the intervention. This generated some frustration in the patients who saw in surgery a way to go back to a good quality of life.

The impact of COVID-19 on my knee [with OA] was that I was forced to postpone surgery which should have taken place in February, to 6 or 7 months later. (Participant 9, female, retired).

\section{Subtheme 3B: Being Limited in Undergoing Routine Medical Visits}

Several participants perceived limitations regarding other medical visits, not strictly related to OA. Some of them had different comorbidities (eg, gynaecological, cardiovascular, gastrointestinal, etc), and they had their visits postponed since public hospitals had to curtail non-urgent procedures. Considering the elevated cost of private care, the interviewees felt that they had no alternative other than waiting for their visits to be rescheduled, which contributed to the perceived impact of COVID-19 in this subtheme.

I have to do this check every year, as it is mandatory for me. However, now, I can't do it, as it is not possible to book [a visit in a public hospital] and, for now, I cannot afford private healthcare, so I'll have to wait. (Participant 7, female, employed). 
As far as I'm concerned, there are some visits and tests I need to do. Unfortunately, some of them privately. After waiting to be contacted by the hospital for a year and a half, they finally called me back just to tell me that they had to postpone all of them, because of COVID-19. (Participant 11, male, employed).

Not only were the participants forced to postpone their routine visits, but they also had difficulties in getting in contact with their general practitioners (GPs) due to the sudden workload increase GPs experience for the COVID-19 pandemic outbreak.

After the COVID-19 pandemic outbreak, it is almost impossible to go there [to the GP]. (Participant 8, male, retired).

\section{Theme 4: Being Unaware of the Importance of Physical Activity as First-Line Interventions}

The participants were not used to do physical activity and seeking physiotherapy also before the pandemic. In line with this, two subthemes were identified: Lack of Seeking of Physical Activity Before the Pandemic and Lack of Seeking of Physiotherapy for $O A$ Before the Pandemic.

\section{Subtheme 4A: Lack of Seeking of Physical Activity Before the Pandemic}

Except for one interviewee, all the participants in this study affirmed that they were not doing any before the COVID-19 pandemic, or they thought that they could not do exercise because of the severity of their disease.

At that time [before the COVID-19 pandemic outbreak], I was not going to the gym anymore. I had not renewed my membership because it was difficult for me to go because of my symptoms. (Participant 4, female, employed).

... On my own initiative. I have never been pushed to do certain treatments [active exercise] in order to take care of osteoarthritis ... then COVID-19 has nothing to do with it [my not taking care of OA right now, during the pandemic]" (Participant 11, male, employed).

\section{Subtheme 4B: Lack of Seeking of Physiotherapy for OA Before the Pandemic}

The reasons behind the lack of seeking physiotherapy for OA also before the COVID-19 pandemic outbreak were expressed by patients in their belief that seeing a physiotherapist was not necessary for their pathology.

I am not aware of their [physiotherapists'] role, so I cannot understand what they can do for my disease. (Participant 2, female, retired).

"I had never thought about it [the role of the physiotherapist], I do not know". (Participant 8, male, retired). exercise nor attending physiotherapy or see a physiotherapist "I was not doing any physiotherapy before the COVID-19 pandemic outbreak, and I am not doing any now" (Participant 6 , male, employed)

Besides, none of the interviewees was ever referred to the physiotherapist by their physicians for their care process before the surgical intervention.

No one has ever suggested me [to go to the physiotherapist] ... No one has ever told me that if I had gone to the physiotherapist twice a week, I would have felt better (Participant 10, male, employed).

No, as I was saying, before the pandemic, I was not seeing a physiotherapist. My doctor has never told me: perhaps it would be good to undertake a care path of this type (Participant 11, male, employed).

\section{DISCUSSIONS}

The COVID-19 pandemic greatly impacted the quality of life and the care process of people with different chronic conditions. This study describes the experience of patients with hip and knee OA in Italy, a country that was severely hit by this health emergency. From our results, several spheres of patients' life were hindered, in particular their social life and the quality of care they received, as discussed hereafter. However, although the outbreak of the pandemic greatly impacted the well-being of the Italian population, ${ }^{2}$ the interviewees seemed to have developed strategies for an effective acceptance of the situation even if some of them were worried about their relatives' health.

Social restrictions imposed by the pandemic had a detrimental effect on social interaction and relationships, in particular for older people already exposed to these burdensome issues. ${ }^{33}$ This was also emphasised in our study, where older interviewees felt a sense of frustration for not being able to see their relatives. Furthermore, a study by Feng et al highlighted that people whose relatives were working as front-line rescue workers (eg, healthcare professionals) perceived unusual pressure and anxiety for the risks their relatives had to face during the pandemic. ${ }^{34}$ This was also reported in our interviews, where participants seemed to be more worried about their relatives' health than about their own. This is in contrast with what was found for other rheumatic and musculoskeletal disorders, where many patients conveyed fear about the increased risk of infection and severe healthrelated outcomes due to COVID-19 pandemic because of their older age, having chronic conditions, or exposure through the workplace or contact with family members. ${ }^{15}$

As far as the participants' general well-being is concerned, the interviewees seemed to have developed good coping strategies to deal with the pandemic. In particular, they accepted the situation, and they all agreed on the fact that they could not do anything about it, apart from following the rules and waiting for the situation to improve. Besides, they all changed their lifestyle to better adapt to the new reality imposed by the 
COVID-19 restrictions. Higher levels of acceptance relate to a good level of 'psychological flexibility', a psychological construct defined as "the ability to contact the present moment more fully as a conscious human being and to change or persist in behaviour when doing to serve valued ends'. ${ }^{35}$ A study by Kroska et al revealed that higher pandemic-related adversity, lower openness to experience, and lower behavioural awareness (psychological inflexibility) were significantly associated with higher general distress. ${ }^{36}$ In contrast, higher levels of psychological flexibility can help to promote well-being and reduce psychological distress amidst COVID-19 adversity. ${ }^{36}$ Hence, the acceptance attitude shown during the pandemic outbreak might explain the fact that the interviewees did not feel that their general levels of well-being were hindered during this delicate moment.

Conversely, when it comes to their healthcare, the interviewees perceived limitations in undergoing passive treatments to manage OA (eg, hyaluronic injections) that are either considered as complementary interventions or as treatments to avoid by CPGs. In fact, an unexpected result of our interviews was the attitude expressed by the interviewees towards the first-line interventions (ie, therapeutic exercise), that are mainly delivered by physiotherapists. They admitted that they were not used to performing exercise even before the COVID-19 pandemic outbreak and that they considered physiotherapists pivotal in their care only after surgery. This is in line with pre-COVID-19 literature which reported that only a small to moderate percentage of individuals with OA met the recommended physical activity levels. ${ }^{37}$

The interviewees believed that the physiotherapist had a minimal (if any) role in the management of their pathology before surgical intervention. The few participants that hypothesised a role of the physiotherapist in their healthcare process believed that physiotherapy was 'something they had to do while they were waiting for surgery' and that it was something they should try to do, so as to 'relieve' their pain for a while. This lack of awareness of the importance of the treatments mainly delivered by physiotherapists in OA management is still debated, and it might stem from several factors hereafter analysed.

First, the implementation of CPGs for the management of musculoskeletal conditions is suboptimal, ${ }^{38}$ with only $40 \%$ of the people with OA estimated to receive the recommended first-line interventions. ${ }^{39}{ }^{40}$ Moreover, physiotherapists do not seem to be up-to-date when it comes to OA CPGs. ${ }^{41-43}$ In two recent studies, ${ }^{44}$ Italian physiotherapists showed a significant evidence-to-practice gap towards OA CPGs and a lack of Scientific English comprehension skills, which can result in suboptimal care for people with OA and may foster an incorrect perception of non-surgical treatments among patients. ${ }^{45} 46$ This is in line with what was found in these interviews, in which participants believed that physiotherapy was helpful 'to walk again after surgery' but that it had no or minimal role in the pre-surgical care process. However, a study by Vitaloni et al concluded that patients are seeking non-pharmacological and non-surgical treatments for their conditions which highlights the possibility that patients might be open to undergo exercise and physiotherapy interventions if educated on their benefits and importance. $^{47}$

Second, such a lack of awareness and mismatch between evidence and patients' expectations might stem from the lack of referral by physicians. Among the 11 interviewees, no one had ever been advised to do exercise or had been referred to a physiotherapist, but all of them had attended a clinical encounter either with their GP or with other specialists. This is in line with a study from Okwera and May showing limited understanding of the role of physiotherapists and OA CPGs among the interviewed GPs. ${ }^{48}$ Besides, in our sample, surgical interventions were presented as the only therapeutic options to all the interviewees. The lack of patients' awareness of the recommended treatments combined with the promotion of surgical interventions, even when not necessary, may lead to inadequate management of the disease, ultimately resulting in an increased economic burden to the healthcare system. ${ }^{49}$

Finally, the participants complained about the delays in medical visits not directly related to OA. Delays or disruptions in routine medical care treatments were observed worldwide during the COVID-19 pandemic outbreak. ${ }^{15} 50$ However, in different countries and for different rheumatic and musculoskeletal diseases, digital health strategies have been implemented to substitute or reduce face-to-face visits. ${ }^{51}{ }^{52}$ Conversely, for what concerned our interviewees, none of these strategies were implemented to substitute face-to-face visits and patients reported troubles in getting in contact with their GPs or other healthcare professionals. Medical care delays or disruptions might increase morbidity and mortality risks related to treatable and preventable health conditions. ${ }^{53}$ Moreover, patients may themselves decide to avoid seeking medical care for fear of being infected or as an unintended consequence of the 'Stay-at-home' recommendation. ${ }^{50}$ In this scenario, telerehabilitation and different health strategies can be a valid alternative solution to face-to-face contact, above all since the evidence showed that remote care is generally welcomed by patients. ${ }^{1654}$

Several limitations of this study need to be discussed. First, the participants were interviewed in different periods marked by different governmental restrictions and COVID-19 infection rates, thus introducing a potential selection bias. However, the interviewees reported a similar experience of the COVID-19 pandemic. As a result, no additional codes and insights emerged during the data analysis process, suggesting that the data saturation was reached. Second, all the interviewees lived in similar geographical areas (ie, northern Italy), suggesting that our results are not transferable per se to the other Italian areas. However, northern Italy was among the most affected areas in all Europe ${ }^{55}$ and we believe that, by investigating participants from this area, we likely depicted the worst-case scenario people with OA may have 
experienced during the pandemic. Hence, it is unlikely that our results may have underestimated the effect of the pandemic in this population in Italy. Third, no follow-up sessions were performed with the interviewees, and their situation may have changed throughout the development of the pandemic. However, during the member checking that was conducted at the end of the interview process, the interviewees were asked whether they still agreed with what was mentioned during their interviews and all the participants reported an optimal level of agreement. Future studies should extend our research on a larger sample, throughout the whole country, with mixedmethod studies.

\section{CONCLUSION}

The COVID-19 pandemic and related restrictions impacted the quality of life and the care of patients with hip and knee OA. The social sphere seemed to be the most hindered, as the interviewees felt isolated during the different COVID-19 pandemic waves, as they could not see their relatives face-to-face. However, they developed good coping strategies to deal with the pandemic such as acceptance towards this new situation and a reschedule of their daily routine in order to deploy the extra time they had at home. However, as far as their care is concerned, they had to face a delay of routine medical visits not strictly related to $\mathrm{OA}$ and of other complementary treatments (eg, physical therapies) to manage OA symptoms. Finally, an interesting result that emerged from these interviews was the lack of seeking active treatments (ie, therapeutic exercise) and of physiotherapy, which was already present before the pandemic. These treatments represent firstline management strategies for OA. Therefore, patients' lack of awareness of the importance of these treatments, as well as health professionals' lack of referral to these interventions, may lead to suboptimal health outcomes and inappropriate surgery. It is thus fundamental to find new strategies to support the promotion of education campaigns that focusses on changing patients' and health professionals' beliefs about the importance of first-line interventions to enhance prescriptions of these treatments from the latter and the utilisation of these therapies from the former.

\section{Twitter Simone Battista @SimoneBattista_}

Acknowledgements The researchers would like to thank Ugo Viora, Executive Manager of the Rheumatic Patients Association (AMaR, Associazione Malati Reumatici)—Piemonte, for his important insights during the creation of the interview guide and all the participants that joined the study, who dedicated their time to perform the interviews. This work was developed within the DINOGMI Department of Excellence framework of MIUR 2018-2022 (Legge 232 del 2016).

Contributors SB designed the study, made substantial contributions to acquisition, analysis and interpretation of data and writing the manuscript and, as guarantor, he accepts full responsibility for the conduct of the study. AD designed the study, made substantial contributions to analysis and interpretation of data and writing the manuscript. MM made substantial contributions to analysis and interpretation of data and writing the manuscript. ME made substantial contributions to analysis and interpretation of data and writing the manuscript. AP designed the study, made substantial contributions to analysis and interpretation of data and writing the manuscript. MT designed the study, made substantial contributions to analysis and interpretation of data and writing the manuscript.

Funding The authors have not declared a specific grant for this research from any funding agency in the public, commercial or not-for-profit sectors.

Competing interests None declared.

Patient consent for publication Not applicable.

Ethics approval Ethical approval was obtained from the Ethics Committee for University Research (CERA: Comitato Etico per la Ricerca di Ateneo), University of Genova (approval date: 15/06/2020; CERA2020.07).

Provenance and peer review Not commissioned; externally peer reviewed.

Data availability statement Data are available upon reasonable request. Data are available upon reasonable request to the corresponding author.

Supplemental material This content has been supplied by the author(s). It has not been vetted by BMJ Publishing Group Limited (BMJ) and may not have been peer-reviewed. Any opinions or recommendations discussed are solely those of the author(s) and are not endorsed by BMJ. BMJ disclaims all liability and responsibility arising from any reliance placed on the content. Where the content includes any translated material, BMJ does not warrant the accuracy and reliability of the translations (including but not limited to local regulations, clinical guidelines, terminology, drug names and drug dosages), and is not responsible for any error and/or omissions arising from translation and adaptation or otherwise.

Open access This is an open access article distributed in accordance with the Creative Commons Attribution Non Commercial (CC BY-NC 4.0) license, which permits others to distribute, remix, adapt, build upon this work non-commercially, and license their derivative works on different terms, provided the original work is properly cited, appropriate credit is given, any changes made indicated, and the use is non-commercial. See: http://creativecommons.org/licenses/by-nc/4.0/.

\section{ORCID iDs}

Simone Battista http://orcid.org/0000-0002-7471-1951

Andrea Dell'Isola http://orcid.org/0000-0002-0319-458X

Alvisa Palese http://orcid.org/0000-0002-3508-844X

\section{REFERENCES}

1 Dong L, Bouey J, Bouey J. Public mental health crisis during COVID-19 pandemic, China. Emerg Infect Dis 2020;26:1616-8.

2 Rossi R, Socci V, Talevi D, et al. COVID-19 pandemic and Lockdown measures impact on mental health among the general population in Italy. Front Psychiatry 2020;11:790.

3 Gandolfi M, Donisi V, Battista S, et al. Health-Related quality of life and psychological features in post-stroke patients with chronic pain: a cross-sectional study in the Neuro-Rehabilitation context of care. Int J Environ Res Public Health 2021;18:3089.

4 Turk DC, Fillingim RB, Ohrbach R, et al. Assessment of Psychosocial and Functional Impact of Chronic Pain. J Pain. 2016;17(9):T21-T49.

5 Lentz TA, George SZ, Manickas-Hill O, et al. What general and Pain-associated psychological distress phenotypes exist among patients with hip and knee osteoarthritis? Clin Orthop Relat Res 2020;478:2768-83

6 Gerdle B, Ghafouri B, Ernberg M, et al. Chronic musculoskeletal pain: review of mechanisms and biochemical biomarkers as assessed by the microdialysis technique. J Pain Res 2014;7:313-26.

7 Donisi V, Mazzi MA, Gandolfi M, et al. Exploring emotional distress, psychological traits and attitudes in patients with chronic migraine undergoing OnabotulinumtoxinA prophylaxis versus withdrawal treatment. Toxins 2020;12:577.

8 Gandolfi M, Donisi V, Marchioretto F, et al. A prospective observational cohort study on pharmacological habitus, headacherelated disability and psychological profile in patients with chronic migraine undergoing OnabotulinumtoxinA prophylactic treatment. Toxins 2019:11:504.

9 World Physiotherapy. COVID-19 resources for physiotherapists.

10 Katz JN, Arant KR, Loeser RF. Diagnosis and treatment of hip and knee osteoarthritis. JAMA 2021;325:568-78.

11 Fernandes L, Hagen KB, Bijlsma JWJ, et al. EULAR recommendations for the non-pharmacological core management of hip and knee osteoarthritis. Ann Rheum Dis 2013;72:1125-35.

12 Bannuru RR, Osani MC, Vaysbrot EE, et al. OARSI guidelines for the non-surgical management of knee, hip, and polyarticular osteoarthritis. Osteoarthr Cartil 2019;27:1578-89. 
13 National Clinical Guidelines Centre. Osteoarthritis: Care and Management in Adults. NICE Clin Guidel. 2014;(177):1-498. London, UK: National Institute for Health and Care Excellence, 2014: 177. 1-498.

14 Swärdh E, Opava CH, Nygård L, et al. Understanding exercise promotion in rheumatic diseases: a qualitative study among physical therapists. Physiother Theory Pract 2021;37:963-72.

15 Michaud K, Wipfler K, Shaw Y, et al. Experiences of Patients With Rheumatic Diseases in the United States During Early Days of the COVID -19 Pandemic. ACR Open Rheuma 2020;2:335-43.

16 Turolla A, Rossettini G, Viceconti A, et al. Musculoskeletal physical therapy during the COVID-19 pandemic: is Telerehabilitation the answer? Phys Ther 2020;100:1260-4

17 Dell'Isola A, Kiadaliri A, Turkiewicz A, et al. The impact of first and second wave of COVID-19 on knee and hip surgeries in Sweden. $J$ Exp Orthop 2021;8:60

18 Booth FW, Roberts CK, Laye MJ. Lack of exercise is a major cause of chronic diseases. Compr Physiol 2012;2:1143-211.

19 Skou ST, Pedersen BK, Abbott JH, et al. Physical activity and exercise therapy benefit more than just symptoms and impairments in people with hip and knee osteoarthritis. J Orthop Sports Phys Ther 2018;48:439-47.

20 Maugeri G, Castrogiovanni P, Battaglia G, et al. The impact of physical activity on psychological health during Covid-19 pandemic in Italy. Heliyon 2020;6:e04315.

21 Hawker GA. Osteoarthritis is a serious disease. Clin Exp Rheumatol 2019;37 Suppl 120:3-6.

22 Jackson J, lyer R, Mellor J, et al. The Burden of Pain Associated with Osteoarthritis in the Hip or Knee from the Patient's Perspective: A Multinational Cross-Sectional Study. Adv Ther 2020;37:3985-99.

23 Jackson J, lyer R, Hubanova P, et al. The burden of osteoarthritis pain from patient's perspective in the United States. Osteoarthr Cartil 2019;27:S248-9.

24 Korstjens I, Moser A. Series: practical guidance to qualitative research. Part 2: context, research questions and designs. Eur J Gen Pract 2017;23:274-9.

25 Moser A, Korstjens I. Series: practical guidance to qualitative research. Part 1: introduction. Eur J Gen Pract 2017;23:271-3.

26 Matua GA, Van Der Wal DM. Differentiating between descriptive and interpretive phenomenological research approaches. Nurse Res 2015;22:22-7.

27 Tong A, Sainsbury P, Craig J. Consolidated criteria for reporting qualitative research (COREQ): a 32-item checklist for interviews and focus groups. Int J Qual Heal Care 2007;19:349-57.

28 Moser A, Korstiens I. Series: practical guidance to qualitative research. Part 3: sampling, data collection and analysis. Eur J Gen Pract 2018;24:9-18.

29 Saunders B, Sim J, Kingstone T, et al. Saturation in qualitative research: exploring its conceptualization and operationalization. Qual Quant 2018:52:1893-907.

30 Vaismoradi $\mathrm{M}$, Turunen $\mathrm{H}$, Bondas $\mathrm{T}$. Content analysis and thematic analysis: implications for conducting a qualitative descriptive study. Nurs Health Sci 2013:15:398-405.

31 Korstjens I, Moser A. Series: practical guidance to qualitative research. Part 4: Trustworthiness and publishing. Eur J Gen Pract 2018;24:120-4.

32 Birt L, Scott S, Cavers D, et al. Member checking: a tool to enhance Trustworthiness or merely a NOD to validation? Qual Health Res 2016;26:1802-11.

33 Harden K, Price DM, Mason H, et al. COVID-19 shines a spotlight on the age-old problem of social isolation. $J$ Hosp Palliat Nurs 2020;22:435-41.

34 Feng Z, Xu L, Cheng P, et al. The psychological impact of COVID-19 on the families of first-line rescuers. Indian J Psychiatry 2020;62:S438-44.
35 Kashdan TB, Rottenberg J. Psychological flexibility as a fundamenta aspect of health. Clin Psychol Rev 2010;30:865-78.

36 Kroska EB, Roche Al, Adamowicz JL, et al. Psychological flexibility in the context of COVID-19 adversity: associations with distress. $J$ Context Behav Sci 2020:18:28-33.

37 Wallis JA, Webster KE, Levinger P, et al. What proportion of people with hip and knee osteoarthritis meet physical activity guidelines? A systematic review and meta-analysis. Osteoarthr Cartil 2013;21:1648-59.

38 Zadro J, O'Keeffe M, Maher C. Do physical therapists follow evidence-based guidelines when managing musculoskeletal conditions? systematic review. BMJ Open 2019;9:e032329.

39 Basedow M, Esterman A. Assessing appropriateness of osteoarthritis care using quality indicators: a systematic review. J Eval Clin Pract 2015;21:782-9.

40 Theis KA, Brady TJ, Sacks JJ. Where have all the patients gone? profile of US adults who report Doctor-Diagnosed arthritis but are not being treated. J Clin Rheumatol 2019;25:341-7.

41 Tang CY, Pile R, Croft A, et al. Exploring physical therapist adherence to clinical guidelines when treating patients with knee osteoarthritis in Australia: a mixed methods study. Phys Ther 2020;100:1084-93.

42 Tittlemier BJ, Wittmeier KD, Robinson DB, et al. Knee osteoarthritis: an investigation into the clinical practice of physiotherapists in Canada. Physiother Canada 2021;73:e20190068:37-46.

43 Holden MA, Waterfield J, Whittle R, et al. How do UK physiotherapists address weight loss among individuals with hip osteoarthritis? A mixed-methods study. Musculoskeletal Care 2019;17:133-44.

44 Battista S, Salvioli S, Millotti S, et al. Italian physiotherapists' knowledge of and adherence to osteoarthritis clinical practice guidelines: a cross-sectional study. BMC Musculoskelet Disord 2021;22:380.

45 Kristensen N, Nymann C, Konradsen H. Implementing research results in clinical practice- the experiences of healthcare professionals. BMC Health Serv Res 2015;16:48

46 Cutolo R, Battista S, Testa M. Actual and perceived level of scientific English across Italian physiotherapy courses: a cross-sectional study. Health Care 2021;9:1135.

47 Vitaloni M, Botto-van Bemden A, Sciortino R, et al. A patients view of OA: the Global Osteoarthritis Patient Perception Survey (GOAPPS), a pilot study. BMC Musculoskelet Disord 2020;21:727.

48 Okwera A, May S. Views of general practitioners toward physiotherapy management of osteoarthritis - a qualitative study. Physiother Theory Pract 2019;35:940-6.

49 Romanini E, Decarolis F, Luzi I, et al. Total knee arthroplasty in Italy: reflections from the last fifteen years and projections for the next thirty. Int Orthop 2019;43:133-8.

50 Masroor S. Collateral damage of COVID-19 pandemic: delayed medical care. J Card Surg 2020;35:1345-7.

51 Kasturi S, Price LL, Paushkin V. Impact of the first wave of the COVID-19 pandemic on systemic lupus erythematosus patients: results from a multi-center prospective cohort, 2021. Available: https://doi.org/101177/09612033211033981

52 Leese J, Backman CL, Ma JK, et al. Experiences of self-care during the COVID-19 pandemic among individuals with rheumatoid arthritis: a qualitative study. Health Expect 2021:1-17.

53 Czeisler Mark É, Marynak K, Clarke KEN, et al. Delay or avoidance of medical care because of COVID-19-Related Concerns - United States, June 2020. MMWR Morb Mortal Wkly Rep 2020;69:1250-7.

54 Mühlensiepen F, Kurkowski S, Krusche M, et al. Digital health transition in rheumatology: a qualitative study. Int J Environ Res Public Health 2021;18:2636.

55 Goumenou M, Sarigiannis D, Tsatsakis A, et al. COVID-19 in Northern Italy: an integrative overview of factors possibly influencing the sharp increase of the outbreak (review). Mol Med Rep 2020;22:20-32. 